\title{
Prioritization of effective factors on job motivation of employees using DEMATEL-AHP method in Payame-Noor University of Khuzestan province
}

\author{
Vahid CHENARI $^{1}$, Asghar AsADI ${ }^{2}$ \\ ${ }^{1}$ Assistant Professor of Administrative Management, Shushtar Branch, Islamic Azad University, \\ Shushtar, Iran \\ ${ }^{2}$ MA Student of Administrative Management, Shushtar Branch, Islamic Azad University, \\ Shushtar, Iran
}

\begin{abstract}
This study aims to prioritize the effective factors on job motivation of employees using DEMATEL-AHP method in Payame-Noor University of Khuzestan province. The study population is all administrative sector employees of Payam-e Noor University in Khuzestan province as 464. The sample size is 169 using Cochran's formula and random sampling method. The data collection measure is AHP, DEMATEL questionnaire. The validity was verified using the experts' panel and Cronbach's alpha was 0.8. The present study is applied, descriptiveanalytic. In the present paper, at first the most effective factors on job motivation (salary, spiritual and organizational motivators) are identified and then a combinational methodology based on AHP models and internal feedbacks of DEMATEL is proposed to prioritize these factors. Finally, the combination of these two views is considered as an important index of relative importance of job motivation factors. According to the results of proposed methodology, "job promotion", "job security” and "job characteristics" were the most effective factors on job motivation. Also, "organizational factors" were in the first priority of significance to enhance job motivation among employees.
\end{abstract}

Keywords: Job motivation factors, Payam-e Noor University, DEMATEL-AHP methodology

\section{Introduction}

One of the important duties of managers in organizations is identification of potential talents of employees to actualize them. We cannot achieve sustainable development without considering productivity and relevant effective factors on production. Human being has a vital role in development and meeting the mental needs of people is of great importance. One of the important duties of manager is motivating employees and considering their requirements to ac achieve organizational goals. In a general classification, motivations are divided into three groups (salary, spiritual and organizational). The employees' requirements at work place including wage, job security and relevant facilities are called salary motivators. Other factors associated to the behavior of others namely organization management meeting social needs are 
called spiritual motivation factors. The organizational motivation factors are those associated to administrative system of the organization.

By appropriate use of the potentialities, the management should actualize them. The evaluation of behavioral methods of employees, desires of employees and their satisfaction has attracted the attention to people motivation. If the requirements of human resources are not met, they leave the organization. The managers of organization should search motivational factors to direct the organization to better efficiency and effectiveness [1]. One of the important items in organizations is man power. Qualified human resources can help the organization with high motivation. In the present era, human resources are the main elements of basic changes in organization and motivating and empowerment of man power is one of the strategic plans of management [2].

\subsection{Statement of problem}

From organizational aspects, motivation is an intrinsic factor changing the behavior and promoting the organizational goals. The resources of each organization are divided into human resources and financial resources. As financial source is used by human resources, optimal use of financial resources is not possible without a motivated force. In the current advanced world, man power is one of the most vital elements in fulfillment of organizational goals [3]. Motivation deals with fulfillment of goals. If people work happily, they can find a significant association between their activities and life. Creating motivation of employees is one of the most important managerial factors in development and productivity of each organization. Motivation is one of the important issues in human resources management and organizational behavior management [4]. Despite the different views on motivation, it has a great position in management, psychology, human resources management and organizational behavior. Service motivation directs the behavior of employees and is effective on quality and quantity of organization activities. The evaluation of effective factors on employees' motivation has great impact on the promotion of organization [5].

\section{Review of literature}

Motivation is an extensive concept. This concept includes other terms describing effective factors on energy and directing our behavior as needs, interest, values, inclination and enticement [6].

The term motivation means movements. Motivation is associated to behavior nature. In other words, no behavior is performed without motivation. Human motivation as conscious or unconscious is based on his needs. In definition of motivation, we can say motivation or need is an intrinsic state or deficiency directing human being to perform some activities [7]. Another definition of motivation is "making efforts to fulfill organization goals and this effort is used to meet one’s demands” [8]. 
Motivation is a chain process starting with need, then request is followed and we are directed to a goal. The consequence of this process leads to the fulfillment of needs. The motivations can entice people to perform their work. In all researches, the position of reward and punishment is considered as strong motivations and money is a reward but it is not the only motivational factor [7].

Motivational theories are classified into content (non-cognitive) theories and process theories (cognitive).

\subsection{Content theories}

Content theories emphasize on intrinsic needs motivating people. If mangers understand the needs of employees, they can direct employees to organizational goals [9].

Indeed, these theories are non-cognitive and show that behavior is predicted without recognition of internal process of thinking. These theories refer to the relationship between an external stimulus and behavior and don't deal with the effect of internal mechanisms.

\subsection{Maslow needs hierarchy theory}

Maslow (1943) presented his theory "hierarchy of needs" and established theory on four aspects:

- $\quad$ Only the unmet need is effective on behavior.

- $\quad$ The people needs are prioritized based on significance.

- $\quad$ When lower level needs are not met, higher level need is not considered.

- $\quad$ If a need is unmet, to meet needs, he remains at the same level.

Maslow classified five need levels including "Physical needs”, “safety needs “,”social needs”, “esteem needs", and “self-realization needs” [9].

\subsection{Herzberg two-dimensional theory}

Herzberg (1959) constructed a two-dimensional paradigm of factors called motivators-hygiene factors. According to the theory, the absence of hygiene factors can create job dissatisfaction. The factors creating satisfaction are called motivators.

He stated that such factors as company policy, supervision, interpersonal relations, working conditions, and salary are hygiene factors. Motivators are achievement, recognition, the work itself, responsibility, and advancement. The most important result of Herzberg et al regarding two-dimensional facto is: the absence of hygiene factors can create job dissatisfaction, but their presence does not motivate or create satisfaction. The absence of motivators creates dissatisfaction and these motivators can lead to better performance [9].

\subsection{McClelland three-dimensional needs theory}


McClelland et al., (1950) divided important needs at work place into the need for achievement, need for power and need of affiliation.

The need for achievement ( $\mathrm{N}$-Ach) is the extent to which an individual desires to perform difficult and challenging tasks successfully. People with a high need for achievement and this motivation are called the need for achievement.

Need for power: The need for power (N-Pow) is a desire for authority, to be in charge.

Those who desire personal power want to direct others and prefer to be in competitive achievements.

The need for affiliation: It is the desire for harmonious relationships with other people. People with high need for affiliation: want to be liked and feel accepted by other people and prefer cooperation over competition [10].

\subsection{Process theories}

Process theories state how employees select their behavior to adapt with their needs. Process theories emphasize on behaviors [9]. These theories are cognitive. People mostly take conscious decisions in their behavior and decision making process should be recognized exactly to make human behave recognition possible [11].

Here, we refer to process theories including “Vroom's expectancy theory”, “ Porter and Lawler expectancy theory”, “Reinforcement theory”, Stacy Adams's equity theory” and "Goal Setting Theory of Edwin Locke”.

\subsection{Vroom's expectancy theory (VIE)}

The initial theory of expectancy was presented for the first time in 1964 by Veroom to create motivation at work place. This theory is based on perception concepts presented by Lewin and Tolman. Vroom believes that one's motivation depends upon his tendency to desires. Motivation depends upon perceived and expected rewards. This theory is based on three key variables of "value”, "instrument” and "expectancy. Three variables of expectancy theories are summarized as:

The relationship between effort and performance shows whether one's effort leads to performance? How much effort is required and what is the success probability?

The relationship between performance and reward shows that how much the individual performance leads to organizational reward or good organizational outcome. 
The relationship between reward and goals shows that how much organization reward is attractive? This factor is associated to the significance of reward given to people and their behavior with unmet needs (Planked et al., 2002).

\subsection{Porter and Lawler expectancy theory}

Porter and Lawler (1968) reviewed the initial theory of Vroom expectancy theory and presented an advanced model. In content theories, it is assumed satisfaction improves performance and vice versa. The two-dimensional model of Herzberg as the best job satisfaction model doesn't focus on the relationship between satisfaction and performance. Vroom model doesn't deal with the relationship between satisfaction and performance. But Porter and Lawler revised Vroom's theory and stated the relationship between satisfaction and performance [12].

\subsection{Reinforcement theory}

Another theory focusing on causes of behavior is "Reinforcement theory". This theory states one's behavior is affected by rewards and punishments experienced in the past in similar situation. For example, an employee who makes efforts to provide a report and is complimented by this chief and this positive reinforcement affects his behavior in next situations.

Based on this theory, most of behaviors of employees are learnt. The employees learn gradually which behaviors are accepted and which behaviors are not accepted. This type of learning is effective on their future behavior.

\subsection{Adams's equity theory}

Another approach in motivation is “Adams's equity theory”. This theory states one's behavior depends upon their perception to justice in behavior. This shows that people compare and judge about the efforts and received reward. People judge equity based on a relatively simple calculation:

- $\quad$ Input: The effort dedicated to a job.

- $\quad$ Outcome or reward: They received reward or outcome based on dedicated outcome [12].

\subsection{Locke goal setting theory}

"Goal setting theory" was presented in the late 1960 by Locke. This theory states that one's behavior is affected by goals determined by them. This theory is similar to expectancy theory as both of them emphasize on conscious selection [13].

\subsection{Local studies}

1- Dr. Mohammad Bagher Kajbaf and Tahere pourkazem in a study "evaluation of the views of employees and supervisors of national oil company of Iran: Determine motivational 
factor and its relationship with job satisfaction” in cognitive science journal 2015, year 12, No. 7 carried out a cross section-analytic study. The study population is all employees and supervisors of audit office of national oil company in Iran in southern oil-field regions, of which 42 employees were selected as sample. To evaluate study variables, a questionnaire of motivational factors and needs of employees and supervisors is used. Also, the questionnaire of job satisfaction of employees and techniques applied by supervisors is used. The results are analyzed using descriptive and inferential statistics, correlation method, t-test, chi-square test and SPSS software. The results show that there was a significant difference between motivational factors from the view of employees and supervisors. The most important need of employees is growth and the highest job satisfaction depends upon type of work and co-workers and lowest satisfaction was dedicated to wage and promotion. It was found that job satisfaction led into achievement of organization goals and living needs were considered for most of employees but the need to respect in society was on priority.

2- $\quad$ Ali Barati (2015) in a study “ evaluation of the relationship between leadership style (based on Likert theory) and motivation of employees in industrial complex of Ehya Sepahan steel and affiliated companies" found that job motivation of supervision had the highest effect and job security had the lowest effect on motivation of employees.

3- Mohammad Taghi Azade Suraki (2015) in his thesis "evaluation of the effective factors on job satisfaction and motivation of employees of electricity production management of Neka" found that in data analysis, descriptive and inferential statistical methods were used. Also, regular random method and data collection measures were used via library method. It was found that the job nature and job work place factors were effective on job satisfaction and motivation of employees.

4- $\quad$ Ahad Motlaghi and Shafikhah (2014) in a study "Evaluation of effective factors on motivation of employees of national company of Iran oil products "showed that spiritual, salary and organizational motivators had the highest effect on increase of motivation of employees. In financial factors, job security, facilities and benefits had the highest effect on increase of motivation of employees.

5- $\quad$ Ali Raghebi (2014) in his thesis in Isfahan University showed that in each organization wage, reward, informal relations, work features, consideration of needs and expectations of employees, mutual consistency between the job and employee, participation of employees in organizational decisions, job security, trust between management and employees, delegation of power by management to employees, academic and job promotion, age and experience were effective on job motivation of employees.

6- $\quad$ Bordbar (2013) in a study "Evaluation of effective factors on motivation of wellbeing experts to enhance mental health of employees" found that motivational factors were salary motivators (job security, benefits, facilities), spiritual factors (job features, interpersonal relations, personality characteristics) and organizational factors (job responsibility, managerial style, job promotion). This study is applied and descriptive (non-experimental) in terms of data collection. The study population is all employees of wellbeing organization as 230. Finally, 168 
questionnaires are collected and applied in descriptive and inferential analyses. Descriptive results showed that organizational factors achieved the mean 3.03, salary motivators mean 3.02 and spiritual factors with the mean 2.39. Among nine effective factors on motivation of wellbeing employees, "wage” dimension with the mean 3053 is in the first rank and "personality properties" dimension with the mean 2.11 is in the ninth rank. The results of first hypothesis test showed that motivation of employees was lower than average. The results of sub-hypotheses test showed that the effect of salary and organizational motivators on motivation of wellbeing employees in Qom province was average and the effect of spiritual factors on motivation of wellbeing employees in Qom province was lower than average. Among nine factors, the effect of

"wage" on motivation of wellbeing employees in Qom province was higher than average. The effect of facilities and safety issues, job participation and responsibility, managerial style, job promotion on motivation of wellbeing employees in Qom province was average.

7- $\quad$ Mohammadzade (2013) in a study "evaluation of job motivation of human resources in Medical Science University of Tehran, Shahid Beheshti, Iran” evaluated the job motivation of 112 employees. The results of study showed that different job factors including interest, intimate relations with co-workers, payment of wage and benefits, job security, facilities were effective on job motivation of librarians. Also, the results showed that by increasing the received wage, one's assurance of his job future and his job motivation are increased.

8- Kohan (2012) evaluated the job motivation of employees working in technical service deputy, public services and national library research of Islamic Republic of Iran with academic education. The results of study showed that motivation of librarians was dependent upon the management policies, welfare, educational facilities, job security promotion and social status.

9- In another study done by Abzari et al., (2010) regarding the effective factors on motivation of employees of state and private hospitals of Isfahan city, the mean of motivational factors (salary, spiritual and organizational) was different in state and private hospitals. In state hospitals, salary motivators had the mean 4.30, spiritual factors with the mean 4.34 and organizational factors with the mean 4.17. In private hospitals, the mean of these factors were as salary motivators 4.18 , spiritual factors 4.12 and organizational factors 4.08 showed significant difference. The results of Fisher test compared to the mean motivational variables in terms of job, employment and degree showed significant difference.

Conclusion: The employees of state and private hospitals had different motivational priorities. In state hospitals, spiritual factors were of great importance compared to private hospitals. The managers of organizations by perceiving these differences in different employees should motivate them.

\subsection{Foreign studies}

1- $\quad$ Parmir and Ist (2015) evaluated job motivation among non-expert employees of 12 automotive units of Ohayo state. The results of study showed that motivation of these employees 
was dependent upon the supervision, co-workers, work identity, benefits and payment, job promotion, probable rewards, working method and communication.

2- $\quad$ Mirfakhrayi studied the correlation of job satisfaction of academic librarians in US and found that academic librarians in small and big libraries of US had positive attitude to their job. There was no significant relationship between the gender of librarians in both groups and their general motivation. Work identity, supervision, wage, promotion and co-workers had high correlation with general motivation of academic librarians (Mirfakhrai. M, 2014).

3- In a paper " modification of health system and motivation of worker in public health (conceptual model) by Limni Miller Franko-Sara binent and Rot Kanfer (2014), a conceptual model was presented and the performance of worker in general health was associated with the worker motivation and availability of resources was necessary but not adequate to increase the performance of the worker. Also, they stated the effective factors on worker motivation in general health and showed how health system had positive effect on worker motivation. They revealed that reformation of health system was effective on motivation of worker and organizational and cultural factors and the worker motivation and organizational and cultural factors were effective on health reforming system.

4- $\quad$ Robert Zavaki and Lura Zavaki (2013) in a paper evaluated how motivation was created by salary motivators. The data analysis was performed using descriptive case statistics, random and simple stratified method. Data collection was performed using library, questionnaire, systematic observation and note taking and referred to motivation creation methods. It was emphasized that most of American companies were only focusing on the needs of employees and managers of US companies based on paying money to their labor increased the motivation of employees and increased productivity and commitment to organization.

In a study done by Chandler, Clare I.R. Chonya, Semkini; Mtei, Frank; Reyburn, Hugh and Whitty, Christopher J.M. (2012) "Motivation, money and respect: A mixed-method study of Tanzanian non-physician clinicians" a mixed-method study was used to evaluate factors affecting motivation amongst these clinicians in Tanzania. Using a conceptual framework of 'internal' and 'environmental' domains known to influence health worker motivation in lowincome countries, developed from existing literature. The survey included all clinicians working in routine patient care at 13 hospitals in the Kilimanjaro and Tangah; 179 in Tanzania. The data collection was conducted using library, interview and questionnaire of five-item Likert scale. For data analysis, descriptive and inferential statistics were used. Salary was thus a clear prerequisite for motivation among clinical psychologists and physicians assistants. The results showed that non-salary motivators were important but satisfaction with the salary was a requirement for each non-salary motivators to create motivation.

6-Kaya (2011) in a study in Ankara showed that employees motivation was dependent upon the work place conditions, fame, respect, job security, promotion, wage, social status, social services and responsibility. 
7-Keynan (2011) in a study "motivation among faculty members of US" found that although the professors of this University were satisfied with their job, work, promotion and co-workers, they were dissatisfied with their wage. The findings showed that three dimensions of job motivation (work satisfaction, promotion and co-workers) had no relationship with gender, age, experience and work but motivation was associated with age, gender, experience and work nature.

Christine Lundberg, Gudmunson and Andersson (2011) in a study "Herzberg's Two-Factor Theory of work motivation tested empirically on seasonal workers in hospitality and tourism" evaluated the seasonal workers in northern Sweden villages (ski) and included two parts of local and migrant communities. The data collection measure was interview and questionnaire of fiveitem Likert scale. The questionnaire was distributed among the entire study population as 613 . The researcher received 243 questionnaires. The data were analyzed using descriptiveinferential statistical methods and study findings showed the verification of two-dimensional Herzberg theory but a difference was revealed between the local and migrant communities: wage was less important compared to the local community in creating motivation for the migrant community and social interaction to create motivation for migrant community had high importance compared to local community.

9-Kalim Yolakhan (2010) in a study "Relationship between reward and motivation in Tejarat bank of Pakistan” showed that descriptive and inferential statistics were used for data analysis. The study sampling was random and simple stratified. The data collection measure was library, questionnaire, interview and systematic observation. It was found that reward increased the motivation of employees. 10-Sipre (2010) evaluated the job motivation of employees of three English Universities of Quebec State of Canada. He used the survey of job motivation with 9 different aspects of job motivation (e.g. wage, promotion, supervision, benefits, probable rewards, instruction, relationship with co-workers and work nature). At first, the results showed the general motivation of this group of employees of their work.

\subsection{Study population and sample size}

The study population is all formal, temporary and part-time personnel of Payame- Noor University of Khuzestan province with Diploma and higher degree as 464 . The sample size is 169 by Cochran's formula. 175 questionnaires were distributed among the participants, of which 155 questionnaires were returned and 20 participants didn’t answer it.

\subsection{Study methodology}

The present study is based on thematic analysis and identification of effective factors on motivation to create a new analytic and operation model and it is also a descriptive-analytic design. The proposed model analyzes the content and identification process of effective factors in the framework of human resources as systematic and presents a new math framework to 
measure and compare relative effects of effective factors on job motivation of employees. Pairwise comparison was performed on job motivational factors via AHP hierarchy analysis method from the view of employees of University and by math computations; the relative weight of factors was extracted. In the second phase, these factors were analyzed based on internal feedbacks and their interacting relationship and in this phase, by math computation, the relative weight of factors was extracted in accordance to DEMATEl methodology. In the third stage, the results of two previous stages were combined and the result was relative weight of factors from combined view (AHP+DEMATEl). Finally, by computation of relative weight of factors from combined view, the relative weight of each of dimensions was achieved. Based on implementation of a hierarchy analysis process for data collection, we refer to the decision maker experts in human resources in Payam-e Noor University. According to AHP method, the survey questions were regarding pairwise comparison of factors in terms of preference between two factors. Regarding the collection of experts opinion about the effect of motivation factors on each other, a questionnaire form with questions regarding the effect of two factors was developed. In the third stage of the combined method, no questionnaire is designed and survey results are combined in a linear convex process and the result of this combination is extraction of final weight of factors and relevant dimensions.

\subsection{Proposed methodology of study}

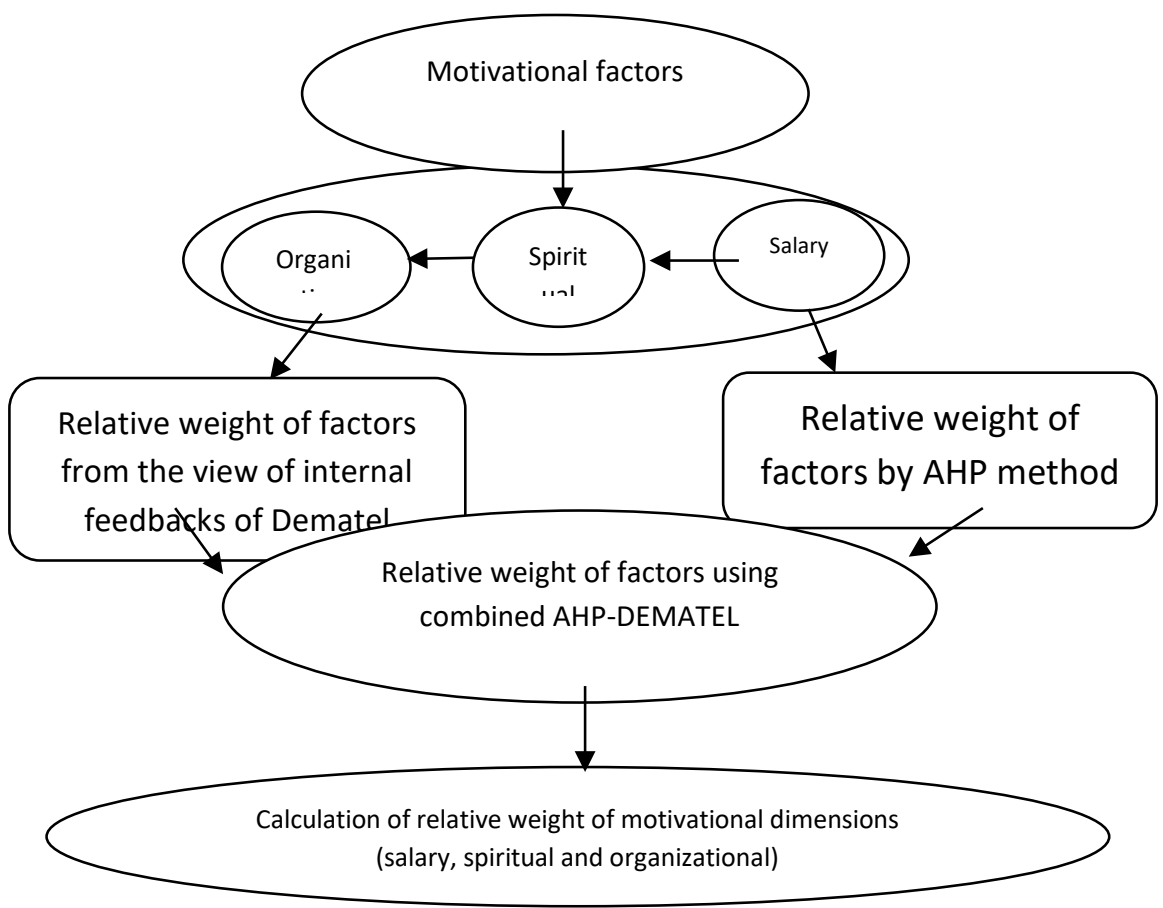

Figure 1: Conceptual model of study 


\subsection{Weight of factors from the view of hierarchy analysis (stage 1)}

Relative importance of black attributes was affected by motivation improvement goals. Taking a decision framework or a method regarding the prioritization of these attributes for validity requires conditions by which personnel and employees of Payam-e Noor University of Khuzestan province can apply their opinion in prioritization. The first stage of the proposed methodology meets the above need and is explained later.

According to AHP, at first pairwise comparison between factors is made and based on relative importance of two comparing factors, the important criterion has 1-9 and finally for each project, a symmetrical matrix is as Equation (1).

$$
A=\left[\begin{array}{cccc}
1 & a_{12} & \ldots & a_{16} \\
a_{21} & 1 & \ldots & a_{26} \\
\vdots & \vdots & \ddots & \vdots \\
a_{61} & a_{62} & \ldots & 1
\end{array}\right]
$$

$a_{i j}$ in Equation (1) indicates the preference of $\mathrm{j}^{\text {th }}$ factor to $\mathrm{i}^{\text {th }}$ factor. For example, if $\mathrm{j}^{\text {th }}$ factor is strongly preferred to $\mathrm{i}^{\text {th }}$ factor, then we give 5 to $a_{i j}$ and 1.5 to ${ }^{a_{j i}}$. From concept view, the reliability of special values is as follows. If the opinion of some experts is used for comparison, these opinions should be combined with each other and this is performed using the geometry mean in Equation (2).

Conceptual value of values 1 ‘2, ‘... 9

Table 1: The preference of factors

\begin{tabular}{|l|l|}
\hline Strongly preferred & 9 \\
\hline Very strong preference & 7 \\
\hline Strong preference & 5 \\
\hline Slightly preferred & 3 \\
\hline Equal preference & 1 \\
\hline $\begin{array}{l}\text { Preferences between the } \\
\text { above items }\end{array}$ & $8,6,4,2$ \\
\hline
\end{tabular}

Here, $\tilde{a}_{i j r}$ is the element in $\mathrm{i}^{\text {th }}$ row and $\mathrm{j}^{\text {th }}$ column of pairwise comparison matrix of $\mathrm{r}^{\text {th }}$ employee and $\mathrm{R}$ denotes the number of employees. 


$$
a_{i j}=\left(\prod_{r=1}^{R} \tilde{a}_{i j r}\right)^{1 / R}, r=1,2,3, \ldots R
$$

After making pairwise comparison matrix, it is required to evaluate its consistency.

To do this, at first, consistency rate (CR) of matrix is computed using Equation (3).

$$
C R=\frac{\lambda_{\max }-n}{R I \times(n-1)}
$$

In the above equation, $n$ is the dimension of matrix, RI consistency rate of random matrix and for $n$ dimensional matrices, the following equation is used.

Table 2: The values of consistency index of random matrix

\begin{tabular}{|c|c|c|c|c|c|c|c|c|c|c|}
\hline $\mathrm{N}$ & 1 & 2 & 3 & 4 & 5 & 6 & 7 & 8 & 9 & 10 \\
\hline $\mathrm{RI}$ & 0 & 0 & 0.58 & 0.9 & 1.12 & 1.24 & 1.32 & 1.41 & 1.45 & 1.45 \\
\hline
\end{tabular}

If CR is smaller than 0.1, the comparisons are acceptable, otherwise the comparisons should be repeated again. After completion of pairwise comparison matrix and support of consistency of comparisons using Equation (4), relative weight vector $\mathrm{w}$ is achieved for the selection criteria.

$$
A w=\lambda_{\max } w
$$

\subsection{The weight of factors from the feedback view (phase 2)}

As it was said, the internal relations of attributes were important factors on prioritization of attributes. The second stage of the proposed methodology was designed based on this issue. In this stage, the capabilities of DEMATEL method are used. This stage is explained as followings. At first, the causal relations between factors are defined and then to show the amount of effects, 0, 1,2,3,4 are used. From conceptual aspects, these values mean "no effect", "weak effect", "average effect", "strong effect" and "very strong effect". Value 0 indicates the states in which there is no significant relationship. The matrix of internal effects of factors is formed as shown in Equation (5). In the matrix, $\mathrm{n}$ is the number of factors and $a_{i j}$ the effect of facto $\mathrm{i}^{\text {th }}$ on factor $\mathrm{j}^{\text {th }}$.

$$
A=\left[\begin{array}{cccc}
a_{11} & a_{12} & \ldots & a_{1 n} \\
a_{21} & a_{22} & \ldots & a_{2 n} \\
\vdots & \vdots & \ddots & \vdots \\
a_{n 1} & a_{n 2} & \ldots & a_{n n}
\end{array}\right]
$$


To adjust the defined effects, at first matrix A should be normalized. To do this, it is required to divide the elements of matrix by the sum of the biggest row (the row with the biggest sum) and this is achieved in Equation (6).

$$
M=\frac{A}{R} \quad, \quad R=\max \left\{\sum_{j=1}^{n} a_{i j} \mid i=1,2, \ldots n\right\}
$$

Matrix $\mathrm{M}$ denotes the direct effect of factors. To consider the indirect effect, Equation (7) is used. Here, I is identical matrix and $\mathrm{F}$ is direct and indirect effect matrix of factors.

$$
F=M(I-M)^{-1}
$$

Finally, as shown in Equation (8), by calculation of the sum of effects of each factor (sum of rows and columns of main diameter elements) and dividing the results on double value of sum of matrix elements, the relative weight vector is computed in which $W_{2}$ is weight vector of factors , $f_{i j}$ element of $i^{\text {th }}$ row and column $\mathrm{j}^{\text {th }}$ of matrix $F$.

$$
W_{2}=\left[\begin{array}{c}
\sum_{j=1}^{n} f_{1 j}+\sum_{j=1}^{n} f_{j 1} \\
\sum_{j=1}^{n} f_{2 j}+\sum_{j=1}^{n} f_{j 2} \\
\vdots \\
\sum_{j=1}^{n} f_{n j}+\sum_{j=1}^{n} f_{j n}
\end{array}\right]
$$

\subsection{Final weight of factors (phase 3)}

To apply and combine the effects of two mentioned views in final prioritization of factors, it is required to combine the weight vectors $\mathrm{W} 1$, W2 of two previous stages. This is done by various methods. We use convex combination method of weights. The mentioned method allows the decision makers to combine the relative weight vectors and increase or decrease the weight effect of each vector based on preferences. In addition, the required final weight vector in this method is normal and we shouldn't make the results normal again. In convex combination of weight vectors, Equation (9) is used.

$$
W=\lambda_{1} W_{1}+\lambda_{2} W_{2} \quad ; 0 \leq \lambda_{1}, \lambda_{2} \leq 1, \quad \lambda_{1}+\lambda_{2}=1_{(9)}
$$

In the above Equation, $1 \lambda, 2 \lambda$ are weight adjustment coefficients of $\mathrm{W} 1$, W2 vectors based on individual or group preferences and $\mathrm{w}$ is the vector of final weights of factors. Finally, by combination of the results of two previous stages, the vector of final weights is achieved. It is worth to mention that based on the analysis of the results of two previous stages, the effect of 
$\mathrm{W} 1$ vector is three times more than $\mathrm{W} 1$ vector. Thus, $1 \lambda, 2 \lambda$ values are $0.75,0.25$, respectively. These values are different based on the other views.

\subsection{The weight of sets (phase 4)}

The effective factors on job motivation are divided into salary, spiritual and organizational motivators. To compute the weight and final priority of each set, the sum of final weight of factors is computed.

\section{Study results}

In this study, by considering two views "hierarchy analysis" and "internal feedbacks" weight vectors of effective factors on job motivation were determined from two mentioned views (first and second phases), then by combining the required weight vectors, the final weight of factors was achieved (third phase). Table 3 shows a summary of results of three stages.

Table 3: Weight vectors and priorities of factors in three phases of proposed methodology

\begin{tabular}{|c|c|c|c|c|c|c|}
\hline \multicolumn{2}{|c|}{ Feedback view } & \multicolumn{2}{|c|}{ AHP view } & \multicolumn{2}{|c|}{ Combined view } & \multirow[b]{2}{*}{ List of factors } \\
\hline $\begin{array}{l}\frac{7}{00} \\
\frac{0}{9} \\
3\end{array}$ & 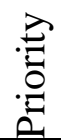 & $\begin{array}{l}\frac{\pi}{00} \\
\cdot \frac{0}{4} \\
3\end{array}$ & 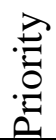 & $\begin{array}{l}\frac{\pi}{00} \\
\cdot \frac{0}{4} \\
3\end{array}$ & $\stackrel{\nexists}{.0}$ & \\
\hline 0.093 & 8 & 0.156 & 2 & 0.140 & 4 & Wage \\
\hline 0.116 & 6 & 0.156 & 2 & 0.146 & 2 & Job security \\
\hline 0.065 & 9 & 0.022 & 9 & 0.033 & 9 & Facilities \\
\hline 0.121 & 3 & 0.148 & 4 & 0.141 & 3 & Job characteristics \\
\hline 0.118 & 4 & 0.057 & 7 & 0.072 & 7 & $\begin{array}{l}\text { Interpersonal } \\
\text { relations }\end{array}$ \\
\hline 0.117 & 5 & 0.129 & 5 & 0.126 & 5 & $\begin{array}{c}\text { Personality } \\
\text { characteristics }\end{array}$ \\
\hline 0.127 & 2 & 0.241 & 1 & 0.213 & 1 & Job promotion \\
\hline 0.103 & 7 & 0.028 & 8 & 0.046 & 8 & Management style \\
\hline 0.140 & 1 & 0.064 & 6 & 0.083 & 6 & Job participation \\
\hline \multicolumn{2}{|c|}{ W2 } & \multicolumn{2}{|c|}{ W1 } & \multicolumn{2}{|r|}{$\mathrm{W}$} & Weight vectors \\
\hline \multicolumn{2}{|c|}{$R_{2}=0.052$} & \multicolumn{2}{|c|}{$R_{1}=0.0107$} & $R=0.017$ & $\begin{array}{l}\text { Variance } \\
\text { range }\end{array}$ & \multirow{2}{*}{$\begin{array}{l}\text { The range and } \\
\text { coefficient of weight } \\
\text { changes of attributes }\end{array}$} \\
\hline \multicolumn{2}{|c|}{$D_{2}=0.453$} & \multicolumn{2}{|c|}{$D_{1}=0.094$} & $D=0.1585$ & $\begin{array}{l}\text { Variance } \\
\text { coefficient }\end{array}$ & \\
\hline
\end{tabular}




\subsection{Data analysis}

In the first column, the factors are listed as final priority and next columns show weight vectors and priorities in three phases. At the bottom of Table, the ranges and coefficients of weight changes of factors are shown in each phase. Based on the results of this Table, the important points are as follows:

Table 4: Weight vector and priority of relevant fields with attributes

\begin{tabular}{|c|c|l|c|}
\hline Priority & Weight vector & \multicolumn{1}{|c|}{ Fields of factors } & No. \\
\hline 3 & 0.318 & $\begin{array}{l}\text { Salary motivators: } \\
\text { Wage, job security and facilities }\end{array}$ & 1 \\
\hline 2 & 0.339 & $\begin{array}{l}\text { Spiritual factors: } \\
\text { Job characteristics, interpersonal relations and job features }\end{array}$ & 2 \\
\hline 1 & 0.343 & $\begin{array}{l}\text { Organizational factors: } \\
\text { Job promotion, management style and job participation }\end{array}$ & 3 \\
\hline
\end{tabular}

Point 1: in the first and second phases of proposed methodology, weighting and prioritization of factors are based on two different views. Thus, we cannot expect the priorities of these two phases are similar completely. For example, according to AHP, some factors including “ job security", "salary" are three important priorities (as common in the second and third priorities) but according to feedback view, these factors have low priority (6, 8, respectively). Some factors including “ job participation” and “job features” are in low priorities based on AHP method (6,4, respectively) and based ono another view, they are in high priorities $(1,3)$.

Point 2: The weight vector and final priorities of motivation factors (Table 3) are achieved in accordance to Equation (9) in previous section and for $\lambda_{1}=0.75, \lambda_{2}=0.25$ values. By increase or decrease of the effect of each of W1,W2 vectors via the change of $\lambda_{1}, \lambda_{2}$ values, we can make some changes in final priorities. Under certain conditions $\lambda_{1} \times \lambda_{2}=0$ means full elimination of the effects of one of two above vectors. Thus, the priority of factors is in accordance to one of the views.

Point 3: The factors are divided into three groups in terms of the fact that each of first and second stages (AHP and internal feedbacks) are included in the first three priorities or not:

First group: The factors that are in the first three priorities in both stages. This group under any certain condition or any convex combination (with the changes of $\lambda 1, \lambda 2$ ) or non-convex 
(multiplication of weight vectors, averaging, etc.) of weight vectors (W1, W2) are among three final priorities. "Job promotion" is the only factor with this benefit.

Second group: The factors in one of two above stages are in the first three priorities. Final priority of these factors depends upon the changes of $\lambda 1, \lambda 2$ coefficients. In other words, under certain conditions in which a factor in first stage (second) is the first three priorities, by increase of $\lambda 1(\lambda 2)$, the factor position in the list of first three priorities in final prioritization is increased and vice versa. Some factors as "salary”, “job security”, “job participation” and "job features” are in this group. For example, "job participation” in the first and second stage is in priorities 6,1. The final priority of this factor with present values $\lambda 1, \lambda 2\left(\lambda_{1}=0.75, \lambda_{2}=0.25\right)$ is 6 . By replacing new values $\left(\lambda_{1}=0.1, \lambda_{2}=0.9\right)$, the reduction of $\lambda 1$ and increase of $\lambda 2$, the final priority of mentioned factor is increased to rank 2.

Third group: The factors that are not the first three priorities in first and second stages, these factors are not placed in the sum of three final priorities. Some factors as "interpersonal relations”," personality characteristics”, “management style”, “facilities and safety”, etc. are in this group.

Point 4: According to the results of Table 3, the range and dispersion coefficient of weights in vector $\mathrm{w}$ is lower than vector $\mathrm{W} 1$ and higher than vector $\mathrm{W} 2\left(R_{1} \geq R \geq R_{2}, D_{1} \geq D \geq D_{2}\right)$. This issue is true under general conditions. In other words, by changing $\lambda 1, \lambda 2$, the range and dispersion coefficient of weights in final stage are changed in the range of equal values in two first phases.

\subsection{Evaluation and explanation of hypothesis test results}

First hypothesis: The importance and relative order of effective factors on job motivation is different in terms of internal feedbacks and hierarchy analysis. In Table (3), the vector of relative weight for effective factors on job motivation in internal feedbacks and hierarchy analysis is different and this means the verification of the above hypothesis. The dispersion coefficient of weights in AHP is higher than internal feedback view. In the past studies, there was no discussion regarding the difference or non-difference of relative importance of effective factors on job motivation from two mentioned views. There was no comparison regarding the consistency or inconsistency of results of present study with the previous studies.

Second hypothesis: The relative importance of effective factors on job motivation from combined view was affected simultaneously with internal feedbacks and AHP.

As shown in Equation (9), the relative importance and weight of effective factors on job motivation from combined view is a convex linear function of relative weights of factors in 
internal feedbacks and AHP. This indicates simultaneous effect of two above views in determining priority and weight of factors in combined view. Thus, second hypothesis is supported. The results of present study are consistent with the results of study of Kajbaf and Pourkazem (2015), Barati (2015), Ahad Motlaghi and Shafikhah (2014), Bakhshi Olyaabad et al., (2014), Raghebi (2014), Kohan (2012), Parmir and Ist (2015), Kaya (2011) and Sipre (2010) and are not consistent with the study of Karbalayi, Tafreshi (2014), Bordbar (2013), Mohammadzade (2013), Abzari et al., (2010), Mirfakhrayi (2014), Chandler (2012), Keyenan (2011), Christian Lundberg et al., (2011) and Kalim Yolakhan (2010).

Third hypothesis: Salary, spiritual and organizational motivators had the highest importance in terms of the effect on job motivation. According to the results of Table (4), organizational factors had the highest relative weight and salary, spiritual and organizational motivators were close and they were in the next ranks. Thus, the above hypothesis is rejected. The results of study are consistent with the results of study of Chandler (2012), Franco et al., (2014), Bordbar (2013), Azade Surki (2015) and are inconsistent with the results of study of Robert Zavaki and Lora Zavaki (2013) and Ahad Motlaghi and Shafikhah (2014).

\subsection{Applied recommendations based on the results of study}

1- $\quad$ As job promotion, job security and job features are the most important factors on job motivation, presenting good education plans at management level of organizations to explain the promotion of these factors among employees can be considered.

2- $\quad$ The proposed methodology of this study is introduced under special conditions to determine and prioritize effective factors on job motivation among employees of Payam-e Noor University of Khuzestan province. With the change of factors, we can develop this methodology for other human resources fields and academic and non-academic organizations.

3- $\quad$ By considering high importance of job promotion, job security and job features, presenting a standard tool to measure the attention of Universities and educational institutes can be proposed.

\section{Suggestions for further studies}

1- $\quad$ According to the proposed methodology to prioritize job motivational factors, hierarchy analysis and internal feedbacks were considered as effective approaches on priority of factors and relevant fields. By referring to the problems of interviewees in responding the questionnaire forms, it is proposed to conduct more studies with the participation of a bigger community of experts to increase accuracy and validity of results of these two views.

2- Based on the internal feedbacks and internal relations of factors, network analytic methods are good tools in the analysis of these relations.

3- In data collection, besides questionnaire, an interview is used to increase accuracy of study. 
Bulletin de la Société Royale des Sciences de Liège, Vol. 85, 2016, p. 1416 - 1433

\section{References}

1. Ahmadi, M. Organizational behavior management. 2013. Sari: Cultural studies publications. First Vol. Third edition.

2. Askarian, M., 2012. The evaluation of job motivation of faculty members of educational deputy of Naja based on Herzberg two-dimensional theory.

3. Ghorbani, R., 2011. The evaluation of needs and intrinsic and extrinsic motivational factors. Journal of behavioral science. Period (2), 91-118.

4. Rhonda, Abrams "successful business research "(2007) prentice hall of India

5. Hamedani, L., 2002. The measure of evaluation of the situation of an organization. Tadbir journal. Ordibehesht 121.

6. Niat, Gage, David; Berliner. Educational psychology. Translated by Gholamreza Khoynejad et al., Mashad, Pazhe. 1995. First edition. P. 470.

7. Seyed Javadin, Seyed Reza. 2007. Theories of management, knowledge view. Third edition.

8. Robins, Stephen p. The basics of organizational behavior. Translated by Dr. Ghasem Kabiri. Second edition. Islamic Azad University publications. 2000.

9. Plunked attner .and Allen. (2002). Management meeting and exceeding customer expectation .u.s.a: Thomson learningRollinson, Derek, aysen brood field and david j

10. Moshabaki, Asghar. 2006. Organizational behavior management. Applied analysis value of human behavior. Tehran. Terme.

11. Mohammadzade, Abbas; Mehrozhan, Armen. 1996. Organizational behavior- contingency attitude. Tehran. Allame Tabatabayi University publications.

12. Borumand, Zahra. 2005. Management of organizational behavior. Tehran: Payam-e Noor University.

13. Weiss,joseph w.(2001) . organizational behavior diversity, gross cultural dynamic and ethic .(2.ed ).south - western college , u.s.: thomsonlearning. 